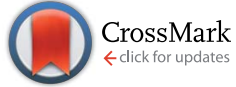

Cite this: J. Mater. Chem. B, 2015, 3, 1379

Received 27th October 2014 Accepted 22nd December 2014 DOI: $10.1039 / c 4 t b 01776 e$ www.rsc.org/MaterialsB

\section{Bioactive organic/inorganic hybrids with improved mechanical performance}

\author{
Ailing Li, ${ }^{a}$ Hong Shen, ${ }^{a}$ Huihui Ren, ${ }^{a}$ Chen Wang, ${ }^{a}$ Decheng Wu, ${ }^{a}$ Richard A. Martin ${ }^{* b}$ \\ and Dong Qiu*a
}

New sol-gel functionalized poly-ethylene glycol (PEGM) $/ \mathrm{SiO}_{2}-\mathrm{CaO}$ hybrids were prepared with interpenetrating networks of silica and PEGM through the formation of $\mathrm{Si}-\mathrm{O}-\mathrm{Si}$ bonds. Bioactive and mechanical properties were investigated for a series of hybrids containing varying organic/inorganic ratios and PEG molecular weights. In contrast to the unmodified $\mathrm{PEG} / \mathrm{SiO}_{2}-\mathrm{CaO}$ hybrids, which rapidly dissolved and crumbled, the epoxy modified hybrids exhibited good mechanical properties and bioactivity. The compressive strength and Young's modulus were greater for higher molecular weight PEGM hybrids (PEGM600 compared to PEGM300). Compressive strengths of $138 \mathrm{MPa}$ and $81 \mathrm{MPa}$ were found for the $50: 50$ and $60: 40$ organic/inorganic hybrid samples respectively, which are comparable with cortical bone. Young's modulus values of $\sim 800 \mathrm{MPa}$ were obtained for the $50: 50$ and $60: 40$ organic/inorganic hybrids. Bioactivity tests were conducted by immersing the hybrids into simulated body fluid and observing the formation of apatite. Apatite formation was observed within 24 hours of immersion. PEGM600 hybrids showed enhanced apatite formation compared to PEGM300 hybrids. Increased apatite formation was observed with increasing organic/inorganic ratio. $70: 30$ and $60: 40$ hybrids exhibited the greatest apatite formation. All PEGM hybrids samples had good cell viability and proliferation. The 60:40 PEGM600 hybrids displayed the optimal combination of bioactivity and mechanical strength. The bioactivity of these hybrids, combined with the enhanced mechanical properties, demonstrate that these materials have significant potential for bone regeneration applications.

\section{Introduction}

Bone is the most widely transplanted material, with the exception of blood. ${ }^{1}$ Each year more than 2.2 million bone graft operations are performed to repair bone defects in orthopaedics and dentistry. ${ }^{2,3}$ Bioactive glasses represent one of the most promising synthetic bone replacement materials; these materials have the potential to be more bioactive than calcium phosphate-based materials. Bioactive glasses, developed by Larry Hench in 1969 show class A bioactivity; they bond to bone and stimulate new bone growth even away from the glass-bone interface. ${ }^{4,5}$

Melt-derived Bioglass ${ }^{\circledR}\left(46.1 \% \mathrm{SiO}_{2}, 24.4 \% \mathrm{Na}_{2} \mathrm{O}, 26.9 \%\right.$ $\mathrm{CaO}$, and $2.6 \% \mathrm{P}_{2} \mathrm{O}_{5} \mathrm{~mol} \%$ ) is used commercially in products such as Novabone ${ }^{\circledR}$ and NovaMin ${ }^{\circledR}$ for repairing bone defects and re-mineralizing dental enamel.,6 Under physiological conditions the glass slowly dissolves releasing controlled amounts of $\mathrm{Ca}, \mathrm{P}$ and $\mathrm{Si}$. The soluble $\mathrm{Ca}$ and $\mathrm{P}$ then precipitate onto the surface to form an amorphous calcium phosphate

${ }^{a}$ Beijing National Laboratory for Molecular Sciences, State Key Laboratory of Polymer Physics and Chemistry, Institute of Chemistry, Chinese Academy of Sciences, Beijing 100190, China. E-mail: dqiu@iccas.ac.cn

${ }^{b}$ School of Engineering \& Applied Science and Aston Research Centre for Healthy Ageing, University of Aston, Birmingham, B4 7ET, UK. E-mail: r.a.martin@aston.ac.uk layer which then crystallizes into apatite (the mineral component of bone). ${ }^{7}$ Studies have shown that the controlled release of $\mathrm{Ca}, \mathrm{P}$ and $\mathrm{Si}$ can stimulate gene transcription in osteoblasts. ${ }^{\mathbf{8}, 9}$ The glass surface also supports cell adhesion and proliferation. There are however limitations; Bioglass ${ }^{\circledR}$ requires very high processing temperatures $\left(\sim 1400{ }^{\circ} \mathrm{C}^{\mathbf{1 0}}\right)$, is difficult to process into scaffolds, fibres or coatings, and has a very small processing window which can result in crystallization. In addition, melt-quench glasses have low surface areas and low porosity which is not ideal for cell ingrowth or vascularization. Sol-gel derived bioactive glasses have been developed to overcome many of these obstacles. ${ }^{\mathbf{1 1}}$ Sol-gels, prepared using a low-temperature hydrolysis and condensation process, have many advantages compared with their meltquench derivatives. ${ }^{\mathbf{1 2 - 1 4}}$ The sol-gels process has greater versatility; bioactive particles, foams, coatings and fibres can all be prepared using this methodology. The resultant gels have a nanometer-scale textural porosity, high specific surface area and abundant exposed silanol groups on surface. ${ }^{15-17}$ Apatite formation occurs in the macropores resulting in a much greater degree of apatite growth. ${ }^{\mathbf{1 8 , 1 9}}$ Despite their excellent bioactivity and acceptable compressive strength their poor tensile strength and brittle nature has severally limited their applications. 
Sol-gel derived glasses can be combined with organic polymers to improve their mechanical strength and toughness. ${ }^{20,21}$ Bioactive glass particles can be dispersed in a polymer matrix to form composites. ${ }^{22}$ However, the bioactive particles are generally covered by the polymer matrix and are therefore not in direct contact with body fluid before polymer degradation, resulting in slow bonding to bone tissue in vivo. ${ }^{23}$ In addition, the bioactive glass particles are usually on the micrometre-scale, thus likely to cause inhomogeneity. Alternatively, inorganic/ organic hybrids can be synthesised by introducing the polymer at an early stage e.g. around the hydrolysis stage. Organic/ inorganic hybrids show similar improvements in mechanical properties compared to the composites but also show much better bioactivity due to the mixing of glass and polymer on molecular scale. Therefore, hybrids have attracted much attention owing to these advantages.

Hybrids can be classified as class I and class II hybrids according to the interaction between inorganic chains and organic chains. In class I hybrids inorganic chains entangle with organic chains with only weak (hydrogen and/or van der Waals bonding) interactions, whereas by modifying the polymer to react with the inorganic phase strong covalent bonds can be formed (class II hybrids). ${ }^{24}$ Class II hybrids have previously been fabricated using alkoxysilane functionalized polymer as precursors in the form of scaffolds, electrospun fibres or monoliths. ${ }^{25-27}$ These hybrids have been shown to exhibit mechanical properties analogous to human cancellous bones. ${ }^{28-30}$ For example Salinas et al. ${ }^{31}$ have prepared dense and homogeneous crack-free monoliths of PDMS-modified CaO$\mathrm{SiO}_{2}$ system. These hybrids are silicate networks covalently bonded to PDMS which show apatite formation when immersed in simulated body fluid (SBF). It was also shown that their elastic modulus decreased with PDMS content but their apatite forming ability increased with calcium content. ${ }^{32}$ Biodegradable silica/poly( $\varepsilon$-caprolactone) (PCL) have also been prepared, in which hydroxyl groups at either end of the PCL polymer chains were modified with 3-isocyanatopropyl triethoxysilane (IPTS), resulting in a polymer end capped with a triethoxysilyl group. The end capped PCL then was introduced into a sol to synthesize bioactive glass/PCL hybrids. ${ }^{33,34}$ Bioactive silica-poly $(\gamma$ glutamic acid) hybrids have also been obtained by covalently bonding the $\gamma$-PGA and bioactive silica through an organosilane coupling agent, glycidoxypropyl trimethoxysilane (GPTMS), ${ }^{24}$ and calcium was confirmed to be incorporated in the silica network by using calcium alkoxide precursor. However, sometimes the resulting hybrids are not sufficiently hydrophilic for ion exchange with the surrounding physiological fluids. Hydrophilic organic components have been introduced to prepare organic/inorganic hybrids. For example, natural polymer gelatin was functionalized using GPTMS, which was then introduced into a sol of hydrolyzed TEOS to covalently link gelatin to silica with $-\mathrm{Si}-\mathrm{O}-\mathrm{Si}-$. Then the wet gels were freeze dried to form porous scaffolds, the mechanical properties of which are similar to the cancellous bones..$^{35}$ Granqvist et al. have developed PEG/siloxane fibres by functionalising PEG end groups with 3 -isocyanatopropyl triethoxysilane. ${ }^{25}$ The functionalised PEG was incorporated into the siloxane network through covalent bonds resulting in fibres with much higher elasticity compared with non-functionalised fibres. The fibres were shown to be effective substrates for the nucleation and growth of bone-like apatite.

Traditionally calcium has always been incorporated in solgels in the form of calcium nitrate which then requires the solgel to be heated $>400{ }^{\circ} \mathrm{C}$ to burn off the toxic nitrates and for calcium to be incorporated into the silicate network. ${ }^{19,36}$ Nitrates are therefore unsuitable for hybrid materials containing polymers which decompose at high temperatures. However, it has recently been shown that the precursor calcium methoxyethoxide (CME) is suitable introducing calcium into hybrids. ${ }^{36,37}$ Calcium has been shown to enter the silicate network at processing temperatures as low as $60^{\circ} \mathrm{C}$ when using CME.

The purpose of the present study was to prepare homogeneous organic/inorganic hybrid materials for bone repair using low molecular weight $(300,600)$ functionalized PEG. The inorganic phase consisted of $\left(\mathrm{SiO}_{2}\right)_{70}-(\mathrm{CaO})_{30}(\mathrm{~S} 70 \mathrm{C} 30$, the archetypal bioactive sol-gel). The organic phase consisted of polyethylene glycol (PEG), a biocompatible polymer (and bioresorbable for low molecular weight polymers ${ }^{38}$ ) which is completely soluble in both water and ethanol, easy to modify and can be incorporated into typical sols for sol-gel hybrid synthesis. PEG ends were first modified with epoxy ethane, then ammoniapropyltriethoxysilane was added to react with epoxy ethane to form PEG end capped siloxane (PEGM). The organic/ inorganic hybrid materials were prepared by introducing PEGM into the sol-gel process, using TEOS and calcium methoxyethoxide as precursors, so that the silica network and organic polymer form interpenetrating networks at the nanoscale. The aim was to investigate whether this system can improve the mechanical properties of the hybrid materials whilst retaining the apatite forming bioactivity of the inorganic sol-gel phase.

\section{Materials and methods}

\subsection{Materials and sample preparation}

The following precursors were used in the sol-gel preparation: PEG300 (285-315), PEG600 (585-615), ammoniapropyltriethoxysilane (97\%) and methoxyethanol (99.8\%), (3-aminopropyl)triethoxysilane (APTES) (97\%) (Sigma Aldrich), epichlorohydrin, metallic calcium and tetraethyl orthosilicate (TEOS, $\geq 99.0 \%$ ) (Sinopharm Chemical Reagent Co., Ltd).

The preparation was carried out in a 4 step process as shown in Fig. 1.

Calcium methoxythoxide preparation. One gram of Ca metal was added into $24 \mathrm{~mL}$ of methoxyethanol under reflux for $24 \mathrm{~h}$ at $80{ }^{\circ} \mathrm{C} .{ }^{39}$ Calcium methoxyethoxide solution was obtained from the supernatant fluid after centrifuging (Ca-methoxyethoxide, $17 \%$ in methoxyethanol).

Modifying PEG with EO (PEG-EO). PEG (50 mmol) was dissolved in $50 \mathrm{~mL}$ of tetrahydrofuran. Epichlorohydrin $(200 \mathrm{mmol})$ and $\mathrm{NaH}(2.1 \mathrm{~g}, 60 \%$ in mineral oil $)$ were added and the medium was stirred under reflux $\left(66^{\circ} \mathrm{C}\right)$ for $24 \mathrm{~h}$. After the solution cooled to room temperature, $30 \% \mathrm{H}_{2} \mathrm{SO}_{4}$ in methanol was added to neutralize the solution. The solvent and excess epichlorohydrin 


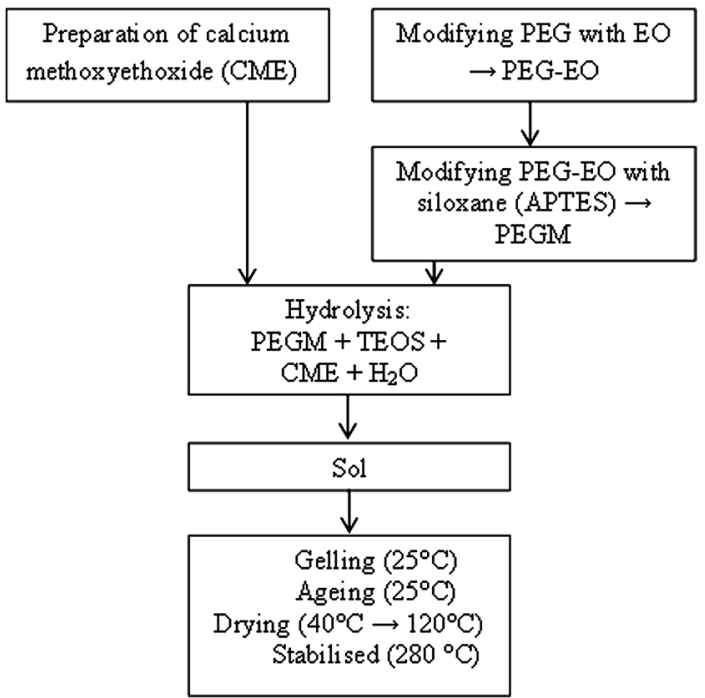

Fig. 1 Flow diagram illustrating the hybrid preparation.

were then removed under reduced pressure. ${ }^{1} \mathrm{H}$ NMR spectra were recorded at $25{ }^{\circ} \mathrm{C}$ on an Avance III 400 spectrometer to confirm the EO modification. Chemical shifts are reported in parts per million (ppm) and a reference standard of $\mathrm{CDCl}_{3}(7.26 \mathrm{ppm})$ was used. FTIR spectra were recorded for PEG, PEG-EO and PEGM using a Bruker Equinox 55 spectrometer to monitor and confirm the reaction process.

Modification of PEG-EO with siloxane (PEGM). PEG300-EO $(4.14 \mathrm{~g}, 0.01 \mathrm{~mol})$ was dissolved into $50 \mathrm{~mL}$ of $\mathrm{CH}_{2} \mathrm{Cl}_{2}, 4.68 \mathrm{~mL}$ (0.02 mol) ammonia propyl triethoxysilicon (APTES) (KH550) was then added and stirred for $24 \mathrm{~h}$ at room temperature. The solvent was removed at reduced pressure. This method was replicated for the PEG600-EO (7.14 g, $0.01 \mathrm{~mol})$ sample.

Preparation of organic/inorganic hybrid material. Under constant stirring PEGM were firstly mixed with TEOS, then Camethoxyethoxide was added at different organic/inorganic molar ratios of $70: 30,60: 40,50: 50$ and $40: 60$ whilst maintaining the inorganic composition of S70C30. After $30 \mathrm{~min}$, water $\left(\mathrm{H}_{2} \mathrm{O} / \mathrm{TEOS}\right.$ $=2$, molar ratio) was added drop wise into the solution and the solution gels within an hour. The resultant gels were aged at ambient temperature for two days then dried in an oven, firstly at $40{ }^{\circ} \mathrm{C}$ for two weeks and then at $120{ }^{\circ} \mathrm{C}$ for a further week. Finally the samples were dried at $280{ }^{\circ} \mathrm{C}$ for $1 \mathrm{~h}$ to ensure full condensation and complete evaporation of the solvent. A control sample of PEG600 with a $60: 40$ organic : inorganic ratio was prepared using unmodified PEG to act as a reference. ${ }^{29} \mathrm{Si}$ solid state MAS NMR spectroscopy experiments were carried out on the dried materials using a Bruker Avance III $400 \mathrm{MHz}$ instrument providing ${ }^{29} \mathrm{Si}$ Larmor frequencies of $79.30 \mathrm{MHz} .4 \mathrm{~mm}$ MAS BB probes spinning at $12 \mathrm{kHz}$ were used. A $2.5 \mu$ s pulse $\left(\sim 60^{\circ}\right.$ tip angle) was used, and the recycle delay was $90 \mathrm{~s} .{ }^{29} \mathrm{Si}$ NMR spectra were referenced using tetramethylsilane $\left(\delta_{\mathrm{Si}}=0 \mathrm{ppm}\right)$.

\subsection{Bioactivity testing}

Bioactivity was tested in vitro by immersing $150 \mathrm{mg}$ monoliths in $100 \mathrm{~mL}$ of simulated body fluid at $36.5 \pm 0.5{ }^{\circ} \mathrm{C}$. SBF was prepared by dissolving reagents $\mathrm{NaCl}, \mathrm{NaHCO}_{3}$, $\mathrm{KCl}, \mathrm{K}_{2} \mathrm{HPO}_{4} \cdot 3 \mathrm{H}_{2} \mathrm{O}, \mathrm{MgCl}_{2} \cdot 6 \mathrm{H}_{2} \mathrm{O}, \mathrm{CaCl}_{2}$, and $\mathrm{Na}_{2} \mathrm{SO}_{4}$ in deionized water. ${ }^{40}$ The solution was buffered to $\mathrm{pH} 7.4$ with Tris(hydroxymethyl)-aminomethane $\left(\left(\mathrm{CH}_{2} \mathrm{OH}\right)_{3} \mathrm{CNH}_{2}\right)$ and hydrochloric acid to give a resultant ion concentration similar to human plasma. After immersing in SBF for different times the samples were washed gently with pure water and left to dry in a desiccator without heating. Apatite formation was evaluated using scanning electron microscopy (SEM), Energy Disperse Xray Spectroscopy (EDXS), Fourier transform infrared (FTIR) and $\mathrm{X}$-ray diffraction (XRD).

SEM/EDXS. Following immersion the samples were dried and then coated with a thin layer of gold $(\mathrm{Au})$ by sputtering (SCD 500). The surface development was observed using a JEOL-6700 instrument operating at a voltage of $15 \mathrm{kV}$.

XRD. Following immersion the samples were dried and then finely powdered. X-ray diffraction spectra were collected using a Rigaku (D/MAX 2500) instrument with $\mathrm{Cu} \mathrm{K} \alpha$ radiation $(\lambda=1.54$ $\AA$ ), operated at $40 \mathrm{kV}$ and $200 \mathrm{~mA}$. Data was collected for $2 \theta$ values between $10^{\circ}$ to $60^{\circ}$ with a step size of $0.02^{\circ}$.

FTIR. Fourier transform infrared spectra were collected in the range $2000-400 \mathrm{~cm}^{-1}$ on a Bruker Equinox 55 instrument. All samples were diluted with dry $\mathrm{KBr}$, ground down to fine powders and pressed into pellets. Measurements were made at ambient temperature.

\subsection{Mechanical testing}

Compressive mechanical properties of the specimens were evaluated using general a purpose-testing machine (Instron3365, Instron Co., Canton, MA, USA) at $23 \pm 2{ }^{\circ} \mathrm{C}$ and $50 \pm$ $5 \%$ relative humidity conditions. Specimens were cut from homogeneous regions of the organic/inorganic hybrids to form blocks measuring $4 \mathrm{~mm} \times 4 \mathrm{~mm} \times 8 \mathrm{~mm}$. These samples were positioned between parallel plates and compressed with a crosshead speed of $0.5 \mathrm{~mm} \mathrm{~min}^{-1}$ and a $5.0 \mathrm{kN}$ load cell. A minimum of five repeats were taken per sample to provide an average. The mean and standard deviation were reported. The Young's modulus was determined from the slope of the initial linear elastic portion of the stress-strain curve. Compressive strength was taken as the maximum strength of the sample until failure and elongation to failure was the percentage strain at fracture.

\subsection{Cell evaluation}

Preparation of hybrids extracts. Organic/inorganic hybrids were soaked in $\alpha$-MEM, preheated to $37{ }^{\circ} \mathrm{C}$, extracting vehicle ratio was $3 \mathrm{~cm}^{2} \mathrm{~mL}^{-1}$, as specified by ISO 10993-12:2007. Organic/inorganic hybrids, which were previously sterilized under UV light for $12 \mathrm{~h}$. After 1,3 and 7 days at $37{ }^{\circ} \mathrm{C}$ under sterile conditions, $\alpha$-MEM was filtered to eliminate hybrids, and these extracts (E1, E2 and E3, respectively) were used as culture medium after adding $10 \%$ fetal bovine serum (FBS)

Cell culture. A preosteoblast cell line (MC3T3-E1; ATCC, CRL-2593, Rockville, MD, USA) was used to investigate the cell compatibility in vitro. The MC3T3-E1 cells were cultured in a humidified incubator under an atmosphere containing $5 \% \mathrm{CO}_{2}$ 
at $37{ }^{\circ} \mathrm{C}$. Dulbecco's Modified Eagle Medium ( $\alpha$-MEM) supplemented with fetal bovine serum (FBS, 10\%), penicillin (100 $\mu \mathrm{g}$ $\left.\mathrm{mL}^{-1}\right)$ and streptomycin $\left(100 \mu \mathrm{g} \mathrm{mL}^{-1}\right)$ was used as the culture medium. Cells were subcultured every 5 days and maintained at $37{ }^{\circ} \mathrm{C}$ in a humidified incubator with $5 \% \mathrm{CO}_{2}$.

Cell viability assays. A Cell Count Kit-8 (CCK-8, Beyotime, Jiangsu, China) was employed to quantitatively evaluate cell viability. ${ }^{41}$ MC3T3-E1 was seeded on 96-well culture plates at a density of $1.7 \times 10^{4}$ cells per $\mathrm{mL}$, after cell adhesion was verified; the culture medium was replaced by different extracts (E1, E2 and E3) of the organic/inorganic hybrids. The cells incubated in $\alpha$-MEM without organic/inorganic hybrids extract were used as a control. The cells were incubated in the culture plates for 3 and 6 days. Then, the CCK- 8 solution $(20 \mu \mathrm{L}$ per well) was added and incubated for $4 \mathrm{~h}$ at $5 \% \mathrm{CO}_{2}$ and $37^{\circ} \mathrm{C}, 100 \mu \mathrm{L}$ of the reacted reagent from each well was transferred to 96 -well plates, and the absorbance at $450 \mathrm{~nm}$ was determined using a micro-plate spectrophotometer (MD, SpectraMax M2, USA). Six parallel replicates of each sample at each time point were prepared so that statistics could be performed.

\subsection{Degradation studies}

Hybrids $(75 \mathrm{mg}$ ) in triplicates were immersed in $50 \mathrm{~mL}$ of SBF at $36.5 \pm 0.5^{\circ} \mathrm{C}$ and stirred at $120 \mathrm{rpm}$. At various time points $(1,4$, $24,72,168,336,504$ and $672 \mathrm{~h}$ ), the hybrids were removed from their respective containers and dried under vacuum prior to weighing. To obtain the rate of weight loss, the initial weight $\left(M_{0}\right)$ of each sample was measured as well as the weight loss at time $t\left(M_{t}\right)$ to give a weight loss\%: weight loss\% $=\left(M_{0}-M_{t}\right) / M_{0}$ $\times 100 \%$. pH values of the extracts were recorded after 1,3 and 6 days immersion.

\subsection{Statistical analysis}

The one-way analysis of variance (ANOVA) was used to evaluate significant differences between means in the measured data. Each experiment was repeated three times. All quantitative data are presented as mean \pm standard deviation.

\section{Results}

\subsection{Sample characterisation}

PEG end groups were successfully modified with epoxy (EO) as shown in Fig. 2. The ${ }^{1} \mathrm{H}$ NMR spectra confirms the addition of the epoxy functional groups. The spectra are assigned as follows: ${ }^{1} \mathrm{H}$ NMR (400 MHz, $\left.\mathrm{CDCl}_{3}\right) \delta(\mathrm{ppm}), 3.58\left(\mathrm{~m}, 1 \mathrm{H}, \mathrm{H}_{\mathrm{e}}\right.$ ), $3.43\left(\mathrm{~m}, 28 \mathrm{H}, \mathrm{H}_{\mathrm{f}}\right), 3.19\left(\mathrm{~m}, 1 \mathrm{H}, \mathrm{H}_{\mathrm{d}}\right), 2.92\left(\mathrm{~m}, 1 \mathrm{H}, \mathrm{H}_{\mathrm{c}}\right), 2.56(\mathrm{~m}$, $\left.1 \mathrm{H}, \mathrm{H}_{\mathrm{b}}\right), 2.38\left(\mathrm{~m}, 1 \mathrm{H}, \mathrm{H}_{\mathrm{a}}\right) .{ }^{42}$ The reaction process of PEG-EO to PEGM and corresponding FTIR spectra are shown in Fig. 3. A feature at $914 \mathrm{~cm}^{-1}$ appears for PEG-EO which is consistent with an epoxy group. ${ }^{\mathbf{4 3 4} 4}$ The epoxy peak then disappears for the PEGM as expected (see Fig. 3a bottom). Clear amorphous monoliths were produced as shown in Fig. 4. The orange colour emanates from the CME precursor which is a dark red/brown colour as previously reported.

\subsection{Structural characterisation}

Fig. 5 shows the ${ }^{29}$ Si MAS NMR spectra of (a) PEGM300/TEOS (calcium free) (b) the PEGM/TEOS/CME hybrid and (c) the unmodified PEG300/TEOS/CME hybrid. The modified PEG hybrids (samples a and b) both show the presence of $\mathrm{T}^{n}$ and $\mathrm{Q}^{n}$ species $\left(\mathrm{T}^{n}\right.$ and $\mathrm{Q}^{n}$ correspond to the structure of $\mathrm{CSi}(\mathrm{OSi})_{n}$ $(\mathrm{R})_{3-n}$ and $\mathrm{Si}(\mathrm{OSi})_{n^{\prime}}(\mathrm{R})_{4-n^{\prime}}$ respectively, where $\mathrm{R}$ is a nonbridging oxygen). In contrast the unmodified PEG hybrid (sample c) only showed the presence of $\mathrm{Q}^{n}$ species. Results of the Gaussian fitting of $\mathrm{T}^{n}$ and $\mathrm{Q}^{n}$ distributions of the ${ }^{29} \mathrm{Si}$ MAS NMR spectra are summarised in Table 1 . The ratio of $\mathrm{T}^{3} / \mathrm{T}^{\text {tot }}$ and $Q^{4} / Q^{\text {tot }}$ in Table 1 show the degree of condensation of the PEGM and silica network respectively. For the TEOS-derived silica network, ${ }^{29} \mathrm{Si}$ exhibit several overlapping contributions associated with $\mathrm{Q}^{n}$ units: three resonances at $\sim-95, \sim-101$ and $\sim-110$ ppm were assigned to $\mathrm{Q}^{2}, \mathrm{Q}^{3}$ and $\mathrm{Q}^{4}$ units respectively. In addition to these $\mathrm{Q}^{n}$ resonances, the ${ }^{29} \mathrm{Si}$ MAS NMR spectra of sample $\mathrm{a}$ and $\mathrm{b}$ showed two peaks at $\sim-60$ and $\sim-65 \mathrm{ppm}$ characteristic of $\mathrm{T}^{2}$ and $\mathrm{T}^{3}$ units resulting from the hydrolysis/ condensation of the terminal triethoxysilane groups of PEGM. Despite poly-condensation between PEGM chains not being excluded, the high occurrence of $\mathrm{T}^{3}$ units suggests that PEGM is successfully grafted to the BG network, thereby coupling the organic and inorganic parts of the hybrid to form a Class II hybrid. Sample a had higher $\mathrm{T}^{3} / \mathrm{T}^{\text {tot }}$ and $\mathrm{Q}^{4} / \mathrm{Q}^{\text {tot }}$ values compared to samples $\mathrm{b}$ and $\mathrm{c}$, which suggests that the silica species were highly condensed.

\subsection{Bioactivity}

Apatite formation was observed on the monolith's surface after immersion in SBF. Fig. 6 illustrates a representative SEM image showing both hemispherical and needle like apatite formation. Needle like formations are consistent with previous reports of apatite formation on bioactive sol-gels. ${ }^{45}$ Apatite formation occurs within 24 hours of immersion and become denser with increasing time.

X-ray diffraction results are shown in Fig. 7-9. Fig. 7 illustrates the formation of apatite as a function of SBF immersion time for PEGM600 with an organic/inorganic molar ratio of 60 : 40. HA diffraction peaks appear after only 24 hours and then increase in magnitude after 3 and 7 days confirming apatite formation on the surface of these materials. Monoclinic HA is shown for reference standard. ${ }^{46}$ Fig. 8 and 9 show the apatite diffraction peaks as a function of organic/inorganic ratio for the PEGM600 and PEGM300 hybrids respectively.

The intensity of the apatite diffraction peaks increases with increasing organic/inorganic ratio for both PEGM600 and PEGM300 hybrids. It is evident that the $60: 40$ and $70: 30$ hybrids show the greatest bioactivity (apatite formation). For all organic/inorganic ratios the PEGM600 spectra shows significantly more apatite formation demonstrating that PEGM600 hybrids are more bioactive compared to their equivalent PEGM300 counterparts.

EDXS results are shown in Fig. 10 as a function of SBF immersion time. Prior to immersing in SBF, the hybrid surface consisted of $\mathrm{Si}, \mathrm{C}$ and $\mathrm{O}$ as expected. Within a day of immersion 


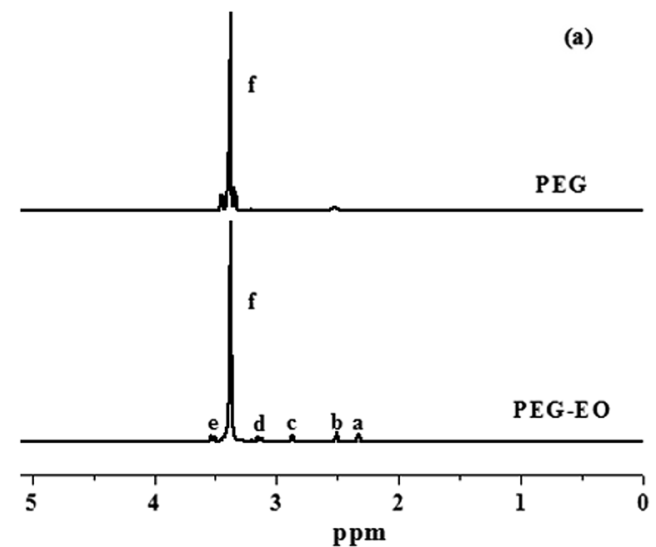

(b)

Fig. 2 (a) ${ }^{1} \mathrm{H}$ NMR spectra of PEG (top) and the modified PEG-EO polymer (bottom), (b) illustrates the reaction process of PEG to PEG-EO.

in SBF the hybrid surface is rapidly covered with a calcium phosphate layer as expected, in addition the $\mathrm{Si}$ and $\mathrm{C}$ signal from the bulk hybrid is significantly attenuated by the $\mathrm{Ca} / \mathrm{P}$ surface formation. The $\mathrm{Ca}$ and $\mathrm{P}$ signals continue to increase with time ( 3 and 7 day immersion) and the Si signal is further attenuated.
FTIR spectra are shown in Fig. 11. The pronounced band $\sim 1090 \mathrm{~cm}^{-1}$ and the smaller peak $\sim 790 \mathrm{~cm}^{-1}$ are attributed to Si-O-Si vibrations..$^{47}$ The broad band $\sim 3440 \mathrm{~cm}^{-1}$ and the sharper peak $\sim 1630 \mathrm{~cm}^{-1}$ are attributed to $\mathrm{O}-\mathrm{H}$ stretching. ${ }^{47}$ Peaks at $\sim 459,567$ and $607 \mathrm{~cm}^{-1}$ are attributed to phosphate

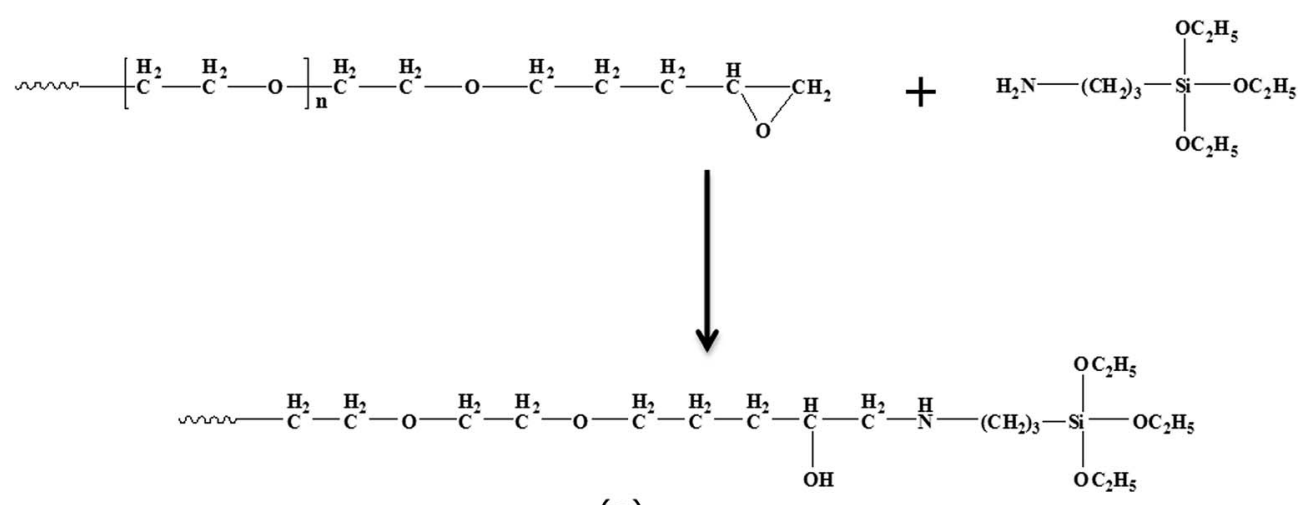

(a)

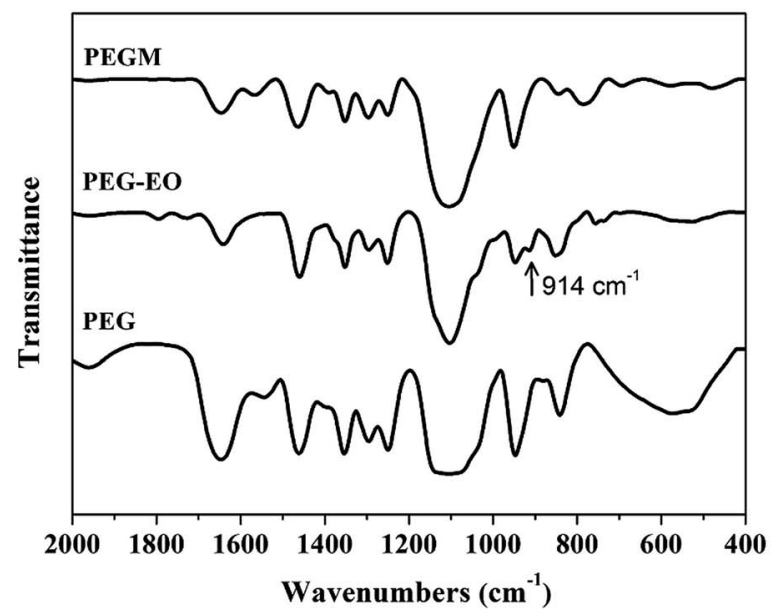

(b)

Fig. 3 (a) Reaction process illustrating the modification of the PEG-EO end groups, (b) FTIR spectra of PEG, PEG-EO and PEGM. The epoxide group of PEG-EO appears at $914 \mathrm{~cm}^{-1}$. 


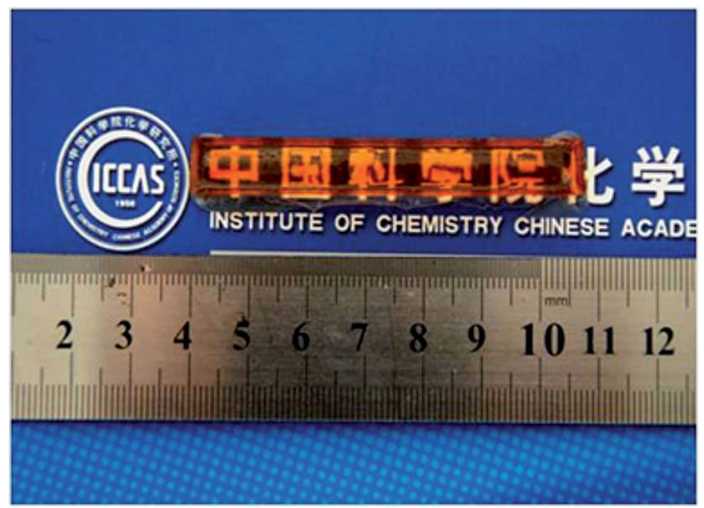

Fig. 4 Photo of the $60: 40$ (organic/inorganic) PEGM600 monolith.

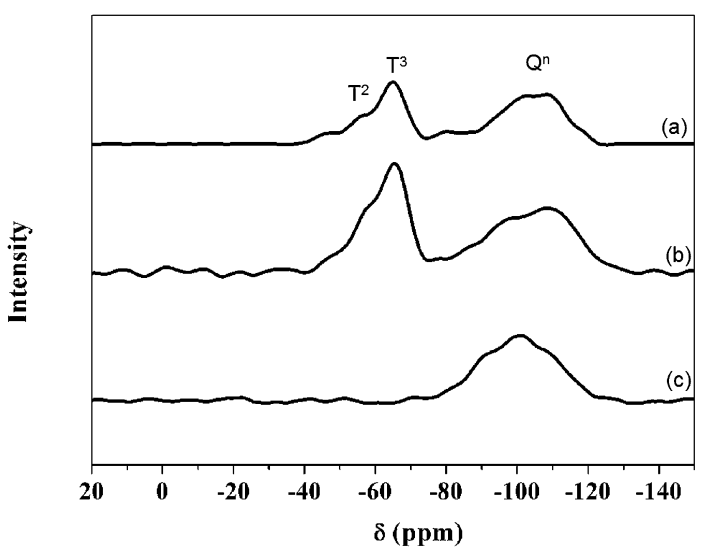

Fig. 5 The ${ }^{29} \mathrm{Si}$ solid state MAS-NMR of the sample obtained from different precursors with the ratio of 60/40 (organic/inorganic, molar\%): (a) - PEGM300/TEOS; (b) - PEGM300/TEOS/CME; (c) PEG300/TEOS/CME.

absorption bands. ${ }^{45}$ These peaks evolve as a function of immersion time in SBF further supporting the formation of phosphates on the hybrids surface.

\subsection{Mechanical testing}

Compressive mechanical testing was performed on the dried hybrid monoliths to test the strength and flexibility of the hybrids. Fig. 12 shows the stress-strain behaviour and effect of organic/inorganic ratio on Young modulus of hybrids, and
Table 2 presents the corresponding Young's modulus and compressive stress data for PEGM300 and PEGM600 samples as a function of organic/inorganic ratio. The elongation to failure was greatly increased to $14-35 \%$ for the hybrids materials compared to $4.2 \%$ for sol-gel glasses (70S30C monoliths, sintered at $\left.800{ }^{\circ} \mathrm{C}\right),{ }^{48}$ indicating improved strain to failure and therefore increased toughness. Two clear trends are also observed; firstly the mechanical properties increase with increasing inorganic ratio. The Young's modulus and compressive strength are greatest for the $50: 50$ hybrid with the overall trend $50: 50>60: 40>70: 30$ and this trend is observed for both the PEGM300 and PEGM600 hybrids. The second point is that Young's modulus and compressive stress are greater for the PEGM600 hybrid compared to its equivalent PEGM300 hybrid (for the same organic/inorganic ratio). The PEGM600 hybrid with a $50: 50$ organic/inorganic ratio was therefore found to have the best mechanical properties with $60: 40$ PEGM600 having very similar Young's modulus values. The unmodified PEG hybrid had very poor mechanical properties and easily crumbled, it was therefore not possible to measure the modulus or strength of these samples. PEG rapidly dissolved from the unmodified composite resulting in just the inorganic phases. Strong covalent links between the organic and inorganic chains are therefore essential in order to obtain tough composites which degrade uniformly acting as a single phase material.

\subsection{Cell viability test}

As shown in Fig. 13, good cell proliferation (96-157\%) was observed in the presence of the three extracts (E1, E2 and E3). Good cell viability was observed for all the extracts, no significant difference in viability was observed for the different extracts after 3 days. However after 6 days the cell viability was higher for the both hybrids compared to the control. The cell proliferation for the PEGM600 hybrids extracts is slightly higher than PEGM300 hybrids (Fig. 13a). The cell proliferation increased with culture time in each group (Fig. 13b).

\subsection{Degradation studies}

A preliminary evaluation of the degradation behaviour of the hybrids was conducted through mass loss upon immersion in SBF solution. Results are summarised in Fig. 14. Mass loss increased rapidly for both samples at during the first week before plateauing at $\sim 43 \%$ at 3 weeks. These results are

Table 1 Chemical shifts and relative proportions of $T^{n}$ and $Q^{n}$ species in Class II PEGM/bioactive silica hybrids synthesised (a) without calcium (b) with calcium methoxyethoxide, (c) unmodified PEG/bioactive silica hybrids. The errors in the chemical shift ( $\delta$ ) are $\pm 0.5 \mathrm{ppm}$, the intensities are $\pm 1 \%$ and the ratios are \pm 0.05

\begin{tabular}{|c|c|c|c|c|c|c|c|c|c|c|c|c|}
\hline Sample & \multicolumn{2}{|l|}{$\mathrm{T}^{2}$} & \multicolumn{2}{|l|}{$\mathrm{T}^{3}$} & \multicolumn{2}{|l|}{$\mathrm{Q}^{2}$} & \multicolumn{2}{|l|}{$\mathrm{Q}^{3}$} & \multicolumn{2}{|l|}{$\mathrm{Q}^{4}$} & $\mathrm{~T}^{3} / \mathrm{T}^{\mathrm{tot}}$ & $\mathrm{Q}^{4} / \mathrm{Q}^{\mathrm{tot}}$ \\
\hline b & -61.0 & 34.3 & -66.2 & 11.0 & - & 0.0 & -101.0 & 45.1 & -112.1 & 9.6 & 0.2 & 0.2 \\
\hline $\mathrm{c}$ & - & 0.0 & - & 0.0 & -95.2 & 60.9 & 100.8 & 3.9 & 108.9 & 35.1 & 0.0 & 0.4 \\
\hline
\end{tabular}



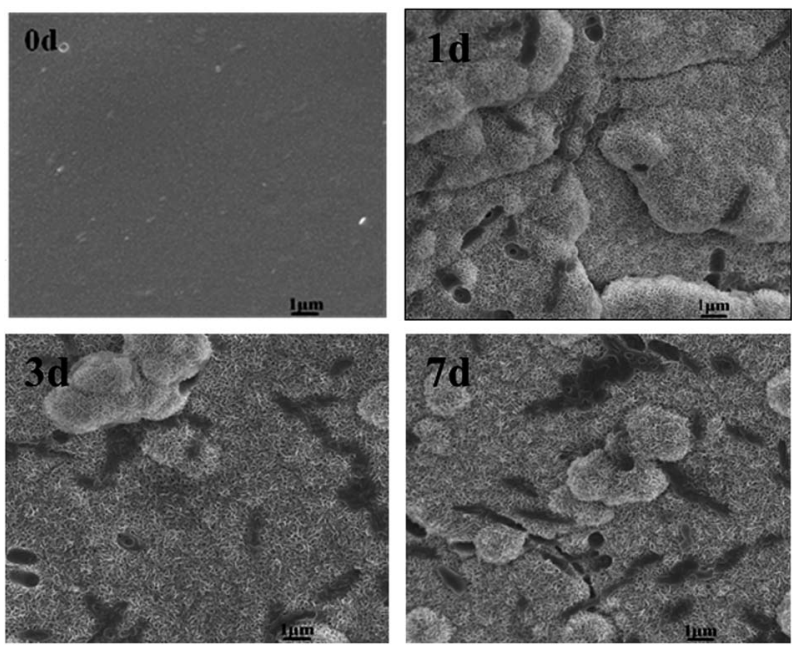

Fig. 6 SEM image of hybrid glasses (PEGM600, organic/inorganic $=$ $60: 40$, molar ratio) after immersion in SBF for 0, 1, 3 and 7 days.

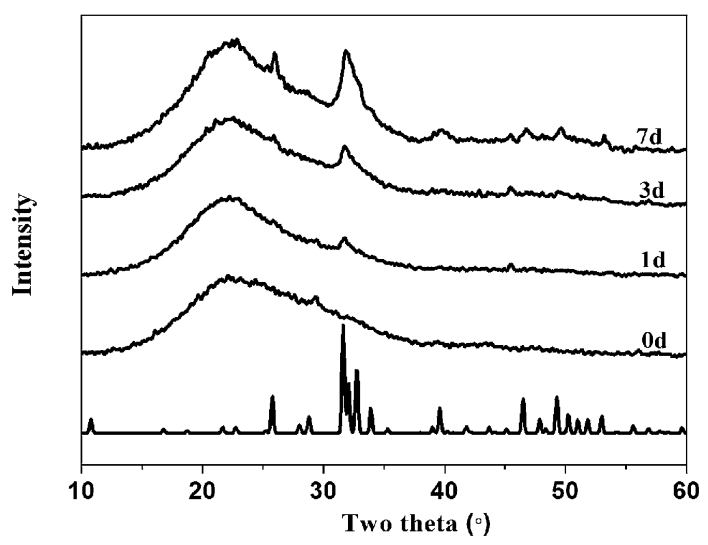

Fig. 7 The XRD spectra of hybrid materials (PEGM600, organic/inorganic $=60: 40$, molar ratio) after immersed in SBF for different times.

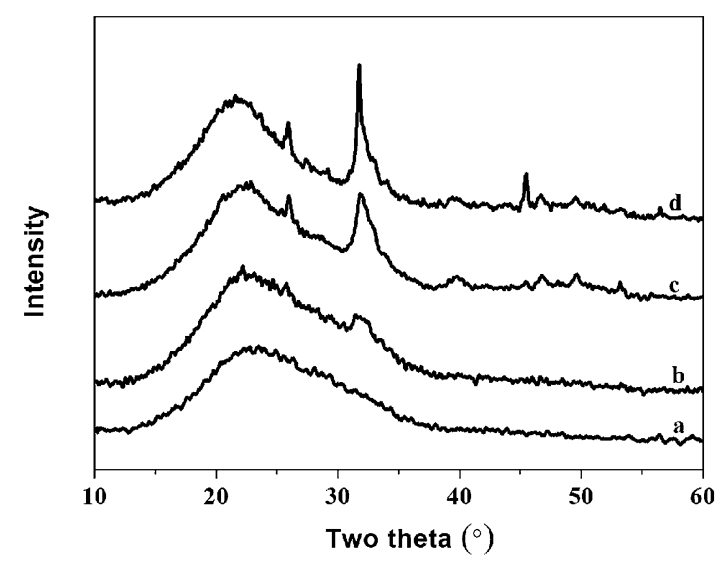

Fig. 8 The XRD spectra of hybrid materials with different organic/ inorganic (molar ratio, PEGM600) after immersed in SBF for 7 days: (a)$40: 60$; (b)-50:50; (c)-60:40; (d)-70:30.

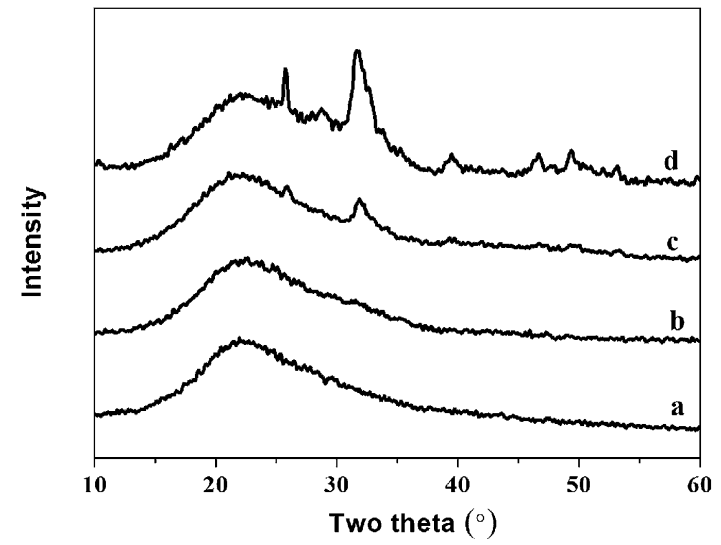

Fig. 9 The XRD spectra of hybrid materials with different organic/ inorganic (molar ratio, PEGM300) after immersed in SBF for 7 days: (a)$40: 60$; (b) $-50: 50$; (c)-60:40; (d)-70:30.

favourable compared to other organic/inorganic hybrids. For example, Russo et al. report mass losses as high as $76 \%$ at 3 weeks for dPEG : GPTMS with a $1: 2$ ratio and losses of $52 \%$ at 3 weeks for dPEG : GPTMS with a $1: 4$ ratio. $^{49}$

Table 3 presents the $\mathrm{pH}$ data for the PEGM600 $60: 40$ and PEGM300 $60: 40$ sample as a function of immersion time. It can be seen that the $\mathrm{pH}$ value of the extracts are stable with only a small increase in $\mathrm{pH}$. The $\mathrm{pH}$ of these hybrids are lower than values reported for NovaBone (7.64) and S70C30 scaffolds (8.19) after immersion for $72 \mathrm{~h} .{ }^{50}$ It has been reported that higher $\mathrm{pH}$ value may be detrimental for cell growth. The PEG modified hybrids exhibit lower $\mathrm{pH}$ values compared to the same inorganic composition (S70C30) this indicates that PEG moieties may help stabilize the inorganic phase of the hybrid.

\section{Discussion}

PEG was successfully modified, via an epoxide functionalization, to yield PEGM/70S30C bioactive hybrids with covalent (Si$\mathrm{O}-\mathrm{Si}$ ) bonds linking the organic and inorganic phases. A series of hybrids containing different organic/inorganic molar ratios and PEG molecular weights were prepared and characterised. In all cases the modified PEGM hybrids showed significantly improved mechanical properties compared to the unmodified PEG hybrids. The improvement in mechanical properties was attributed directly to the covalent bonding between the organic and inorganic phases for the modified PEG hybrids. The present samples exhibited favourable bioactivity and mechanical properties compared to equivalent materials previously reported in the literature. In previously studies, Liu et al. prepared PEG/ $\mathrm{SiO}_{2}-\mathrm{CaO}-\mathrm{P}_{2} \mathrm{O}_{5}$ hybrid xerogels by introducing PEG during the hydrolysis process to provide a molecular scale interaction between the organic and inorganic phases. The PEG molecular chains were found to penetrate into the $\mathrm{SiO}_{2}$ network forming a semi-IPN structure. Since there was no covalent bonding between inorganic and organic phases, although a significantly increase in both the Young's modulus (320 to $420 \mathrm{MPa}$ ) and hardness was achieved compared to the pure inorganic 

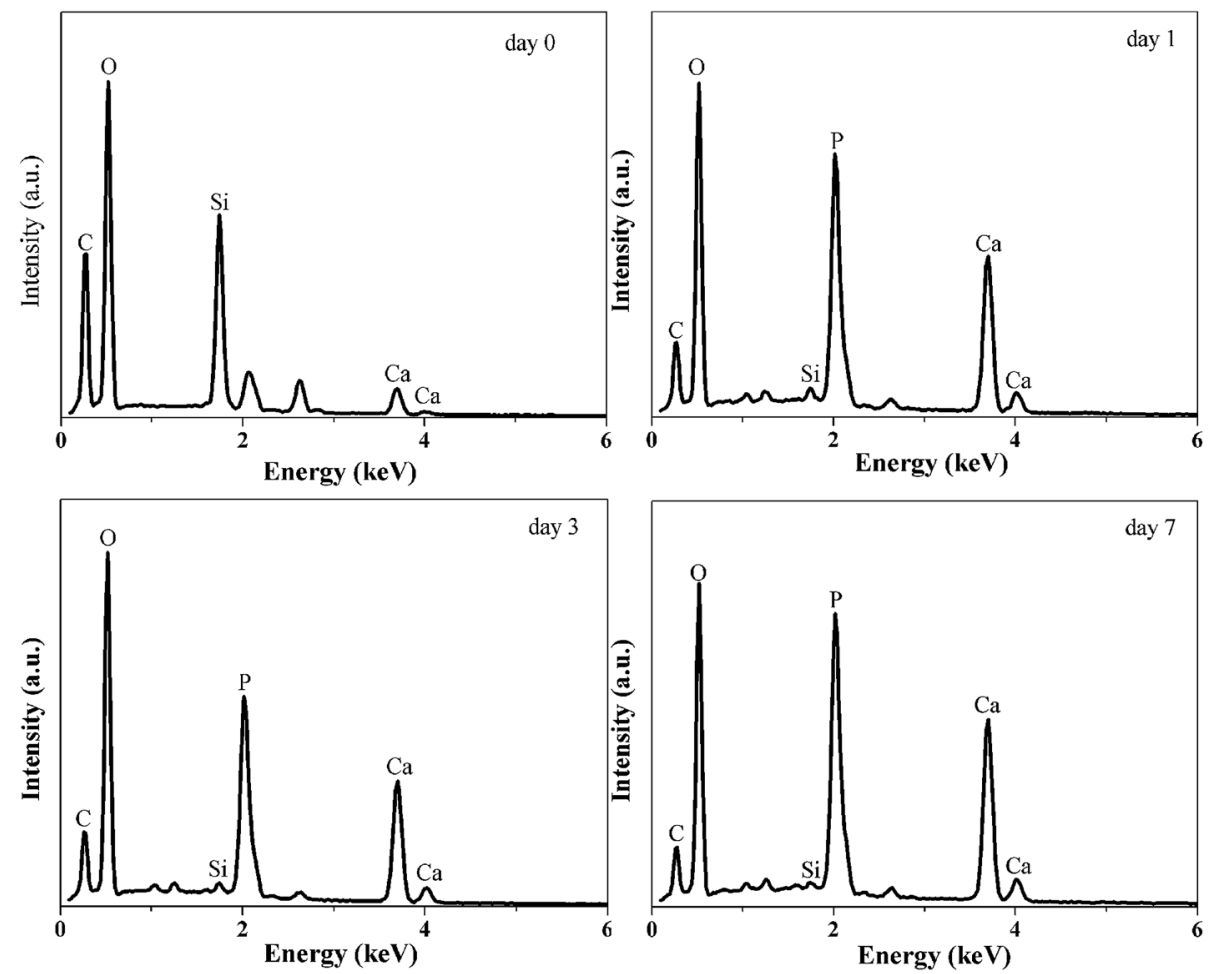

Fig. 10 EDXS spectra of the hybrids surface after immersing SBF for 0, 1, 3 and 7 days.

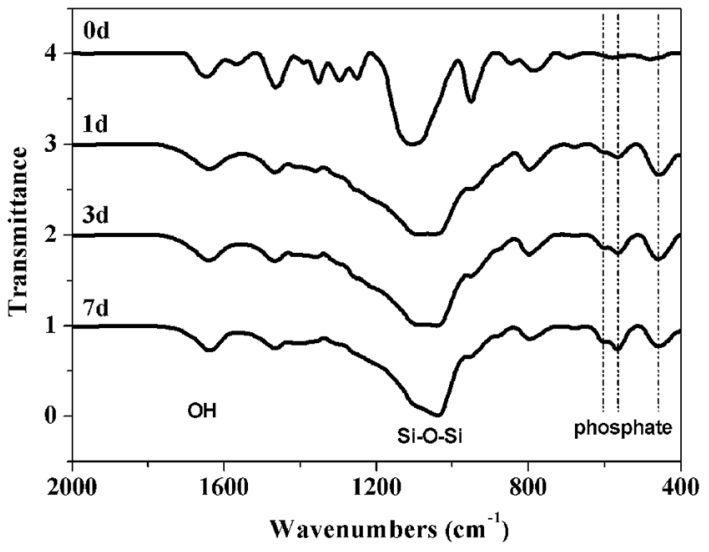

Fig. 11 FTIR spectra of the hybrid materials after immersing SBF for 0 , 1,3 and 7 days.

material, ${ }^{47}$ it still could not reach the level achieved in the present study (in the present study we are achieving Young's modulus values in excess of $800 \mathrm{MPa}$ for PEGM600 $50: 50$ and $60: 40$ hybrids). Wang et al. have developed nanoparticlegelatin composites with enhanced mechanical properties; ${ }^{51}$ the maximum value of Young's modulus reported for these systems was $600 \mathrm{MPa}$ compared to over $800 \mathrm{MPa}$ in the current system.

Rhee has developed poly( $\varepsilon$-caprolactone)/silica hybrids for bone repair applications, with covalent bonding between inorganic and organic phases. ${ }^{33}$ These materials show good apatite forming ability and Young's moduli of 200-600 MPa. Russo et al. have recently developed silica/bis(3-aminopropyl) polyethylene glycol(dPEG) inorganic/organic hybrids by using 3glycidopropyltrimethoxysilane (GPTMS) as a coupling agent to provide the covalent links. ${ }^{49}$ The strain to failure increased from $4.2 \%$ for the sol-gel glass to $8-15 \%$ for the hybrids and compressive strengths of 15-20 MPa were reported which are comparable to cancellous bone (4-12 MPa) but low compared to cortical bone (100-230 MPa). In the present study we are achieving compressive strength values of 138 and $81 \mathrm{MPa}$ for PEGM600 $50: 50$ and $60: 40$ hybrids respectively. In addition to the covalent bonding, the improvement in mechanical properties achieved in our study might be partly due to the choice of molecular weight of polymer segments used. Previous studies have employed polymers with molecular weights greater than $1000 .^{33,49}$ However, the polymer phase is mechanically weaker in compression compared to the inorganic phase. In the present study, PEG600 was found to be better than PEG300 suggesting there is also a lower limit for optimised polymer weight. However, we also note that it was not possible to form monoliths from higher molecular weight PEG (2000, 3000, 4000 and $6000)$. Therefore, an optimal molecular weight of polymer must to be chosen, in order to maximise the toughness of these hybrids.

Apatite formation was observed for $50: 50,60: 40$ and 70 : 30 PEGM600 and $60: 40$ and $70: 30$ PEGM300 hybrids. For a given organic/inorganic ratio the apatite formation of PEGM600 hybrids were consistently higher than the equivalent PEGM300 hybrids; this is attributed to the higher the molecular weight of the polymer. Apatite formation increased with increasing organic content with $60: 40$ and $70: 30$ (organic/ inorganic molar ratio) showing the most promising formation. 

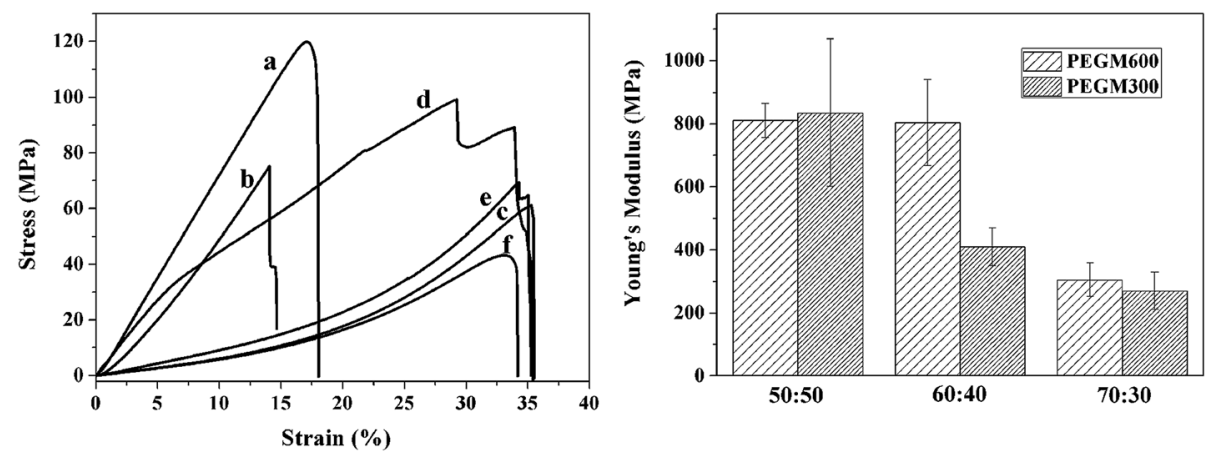

Fig. 12 Stress-strain curves (a) and effect of organic/inorganic ratio on Young's modulus (b) of hybrids obtained by compression test for hybrids with different organic/inorganic ratios (molar\%): curve (a), PEGM600 50 : 50; curve (b), PEGM600 60: 40; curve (c), PEGM600 70: 30 ; curve (d), PEGM300 50 : 50; curve (e), PEGM300 60 : 40; curve (f), PEGM300 $70: 30$.

Table 2 Compressive strength and Young's modulus values of the hybrids, note it was not possible to measure the unmodified PEG samples which crumbled

\begin{tabular}{|c|c|c|c|c|c|}
\hline \multicolumn{3}{|l|}{ PEGM600 } & \multicolumn{3}{|l|}{ PEGM300 } \\
\hline $50: 50$ & $138.1 \pm 36.5$ & $811.2 \pm 53.6$ & $50: 50$ & $128.3 \pm 75.1$ & $834.8 \pm 234.4$ \\
\hline $60: 40$ & $81.4 \pm 5.9$ & $804 \pm 136.6$ & $60: 40$ & $68.1 \pm 12.6$ & $410.1 \pm 59.6$ \\
\hline $70: 30$ & $52.4 \pm 8.98$ & $305.6 \pm 53.6$ & $70: 30$ & $49.17 \pm 15.2$ & $270.1 \pm 60.3$ \\
\hline
\end{tabular}
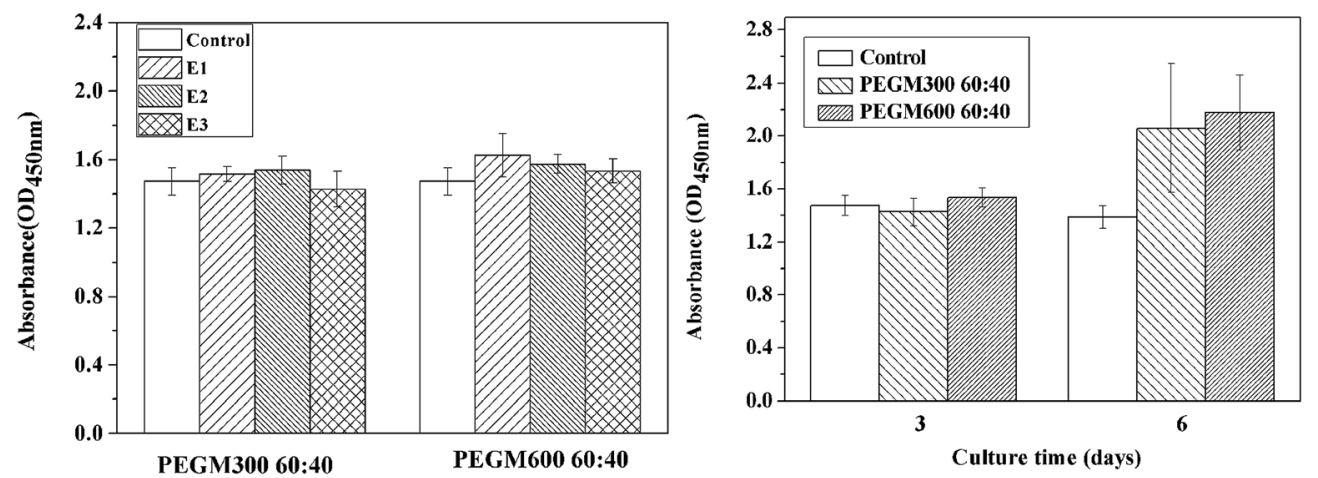

Fig. 13 CCK-8 assay for proliferation of MC3T3-E1 cells cultured with (a) extracts (E1, E2 and E3, respectively) of PEGM300 60:40 and PEGM600 60: 40 for 3 days and (b) extracts (E3) of PEGM300 $60: 40$ and PEGM600 $60: 40$ for 3 days and 6 days.

$50: 50$ and $40: 60$ hybrids showed minimal apatite formation. PEG is hydrophilic and relatively flexible, the increase in apatite formation with PEG molecular weight and PEG content are therefore likely to have resulted from better penetration of SBF into the material. This would enable the simulated fluid to react more quickly with the bioactive inorganic phases.

The 60:40 PEGM600 hybrids were the most promising materials demonstrating both good apatite formation and good mechanical properties. Young's modulus values $\sim 800 \mathrm{MPa}$ are higher than those of cancellous bone and significantly higher than non-functionalised PEG hybrids and other values reported in the literature. Compressive strength of $\sim 80 \mathrm{MPa}$ is similar to values required for compact bone (100 MPa). The excellent biocompatibility and aqueous solubility of PEG molecules, as well as the bioactivity of the inorganic components, coupled with the improved mechanical properties mean these hybrids exhibit great potential for bone regeneration applications.

The hybrids demonstrate good biocompatibility for both cell viability and proliferation. The hybrids exhibit an initial rapid weight loss, which provides the essential release of $\mathrm{Ca}$ and $\mathrm{Si}$ that is necessary for apatite and to stimulate cellular activity. ${ }^{\mathbf{8}, 52}$ After the initial weight loss observed during the first week which peaked at $37 \%$ the weight-loss plateaus and only a further $4 \%$ weight-loss is observed during the subsequent 3 weeks. Apatite 


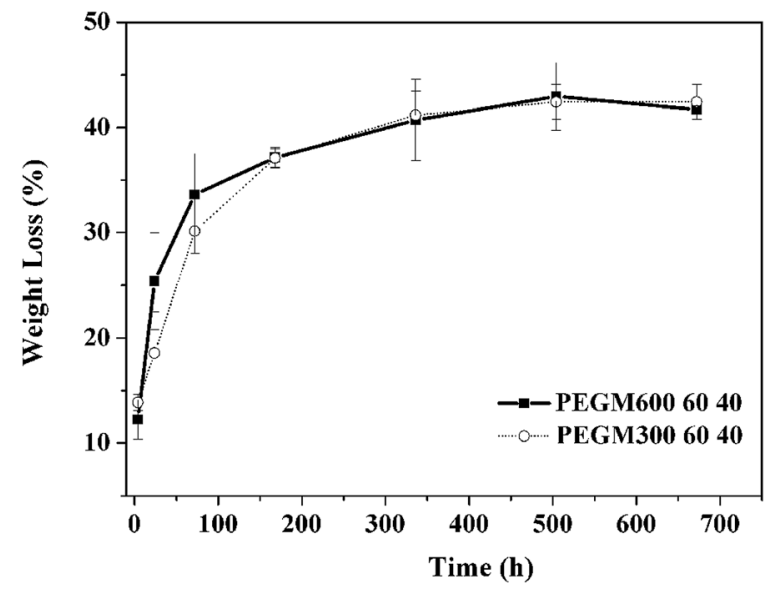

Fig. 14 Degradation assay into SBF solution as a function of soaking time for hybrid materials obtained from PEGM600 and PEGM300 with the organic/inorganic ratio of $60: 40$.

Table $3 \mathrm{pH}$ value of samples after immersion in $\alpha$-MEM

\begin{tabular}{lllll}
\hline Sample & 0 day & 1 day & 3 day & 6 day \\
\hline PEGM600 60:40 & 7.30 & 7.36 & 7.41 & 7.48 \\
PEGM300 60:40 & 7.30 & 7.38 & 7.49 & 7.60
\end{tabular}

formation counteracts further weight-loss after the first week such that the total weight loss after 4 weeks in only $41 \%$.

No significant difference was observed between the PEGM300 and PEGM600 samples. This confirms that the molecular weight has little effect on the degradation of hybrids, and the degradability may be controlled by inorganic phase. During the first week, the mass loss was slightly lower for the PEG300M hybrid; this may be attributed to the higher hydrophilicity and the higher cross-link density of lower molecular weight polymer.

\section{Conclusions}

Functionalised PEGM/70S30C bioactive hybrids were successfully prepared via sol-gel synthesis. PEGM was successfully used as a cross-linking agent between organic and inorganic components at the molecular level. This resulted in strong covalent $\mathrm{Si}-\mathrm{O}-\mathrm{Si}$ bonds between the organic and inorganic phases which significantly improved the mechanical properties of the resultant hybrids. A corresponding increase in the apatite forming ability was observed for increasing molar fraction of the organic phase; at $50 \%$ or below the apatite formation was significantly reduced. Hybrids obtained from higher molecular weight PEGM600 had a higher compressive stress and showed enhanced apatite formation compared to the equivalent PEGM300 hybrid. The $60: 40$ PEGM600 hybrids were the most promising materials demonstrating good apatite formation, cell proliferation and viability and good mechanical properties. These organic/inorganic hybrid materials exhibited improved mechanical properties and excellent apatite forming ability, confirming their potential use as bone regeneration material.

\section{Acknowledgements}

This work was supported by MOST (Project no. 2012CB933200, 2013DFG52300), NSFC (Project no. 51173193) and a Royal Society/Natural Science Foundation of China international exchange grant (IE131323, 513111170).

\section{References}

1 A. Van Heest and M. Swiontkowski, Bone-graft substitutes, Lancet, 1999, 353(suppl. 1), SI28-SI29.

2 P. V. Giannoudis, H. Dinopoulos and E. Tsiridis, Bone substitutes: An update, Injury, 2005, 36, 20-27.

3 K. U. Lewandrowski, et al., Bioresorbable bone graft substitutes of different osteoconductivities: a histologic evaluation of osteointegration of poly(propylene glycol-cofumaric acid)-based cement implants in rats, Biomaterials, 2000, 21(8), 757-764.

4 L. L. Hench, R. J. Splinter, W. C. Allen and T. K. Greenlee, Bonding mechanisms at the interface of ceramic prosthetic materials, J. Biomed. Mater. Res. Symp., 1971, 5, 25.

5 L. L. Hench, The story of Bioglass (R), J. Mater. Sci.: Mater. Med., 2006, 17(11), 967-978.

6 L. L. Hench and I. Thompson, Twenty-first century challenges for biomaterials, J. R. Soc., Interface, 2010, 7, S379-S391.

7 R. A. Martin, et al., A study of the formation of amorphous calcium phosphate and hydroxyapatite on melt quenched Bioglass(A (R)) using surface sensitive shallow angle X-ray diffraction, J. Mater. Sci.: Mater. Med., 2009, 20(4), 883-888.

8 I. D. Xynos, et al., Gene-expression profiling of human osteoblasts following treatment with the ionic products of Bioglass (R) 45S5 dissolution, J. Biomed. Mater. Res., 2001, 55(2), 151-157.

9 I. D. Xynos, et al., Bioglass (R) 45S5 stimulates osteoblast turnover and enhances bone formation in vitro: Implications and applications for bone tissue engineering, Calcif. Tissue Int., 2000, 67(4), 321-329.

10 R. A. Martin, et al., A structural investigation of the alkali metal site distribution within bioactive glass using neutron diffraction and multinuclear solid state NMR, Phys. Chem. Chem. Phys., 2012, 14(35), 12105-12113.

11 R. Li, A. E. Clark and L. L. Hench, An Investigation of Bioactive Glass Powders by Sol-Gel Processing, J. Appl. Biomater., 1991, 2(4), 231-239.

12 R. A. Martin, et al., Characterizing the hierarchical structures of bioactive sol-gel silicate glass and hybrid scaffolds for bone regeneration, Philos. Trans. R. Soc., A, 2012, 370(1963), 1422-1443.

13 D. Arcos and M. Vallet-Regi, Sol-gel silica-based biomaterials and bone tissue regeneration, Acta Biomater., 2010, 6(8), 2874-2888.

14 J. R. Jones, Review of bioactive glass: From Hench to hybrids, Acta Biomater., 2013, 9(1), 4457-4486. 
15 P. Sepulveda, J. R. Jones and L. L. Hench, In vitro dissolution of melt-derived 45S5 and sol-gel derived $58 \mathrm{~S}$ bioactive glasses, J. Biomed. Mater. Res., 2002, 61(2), 301-311.

$16 \mathrm{~S}$. Lin, et al., Tailoring the nanoporosity of sol-gel derived bioactive glass using trimethylethoxysilane, J. Mater. Chem., 2010, 20(8), 1489-1496.

17 J. R. Jones, T. F. Kemp, and M. E. Smith, Effect of OH content on the bioactivity of sol-gel derived glass foam scaffolds, Bioceramics 18, 2006. vol. 309-311, pts 1 and 2, pp. 10311034.

18 M. Vallet-Regi, D. Arcos and J. Perez-Pariente, Evolution of porosity during in vitro hydroxycarbonate apatite growth in sol-gel glasses, J. Biomed. Mater. Res., 2000, 51(1), 23-28.

19 V. FitzGerald, et al., Bioactive glass sol-gel foam scaffolds: Evolution of nanoporosity during processing and in situ monitoring of apatite layer formation using small- and wide-angle X-ray scattering, J. Biomed. Mater. Res., Part A, 2009, 91(1), 76-83.

20 A. R. Boccaccini, et al., Preparation and characterisation of poly(lactide-co-glycolide) (PLGA) and PLGA/Bioglass((R)) composite tubular foam scaffolds for tissue engineering applications, Mater. Sci. Eng., C, 2005, 25(1), 23-31.

$21 \mathrm{~K}$. Zhang, et al., Processing and properties of porous poly(Llactide)/bioactive glass composites, Biomaterials, 2004, 25(13), 2489-2500.

22 K. Rezwan, et al., Biodegradable and bioactive porous polymer/inorganic composite scaffolds for bone tissue engineering, Biomaterials, 2006, 27(18), 3413-3431.

$23 \mathrm{~J} . \mathrm{J}$. Blaker, et al., Mechanical properties of highly porous PDLLA/Bioglass (R) composite foams as scaffolds for bone tissue engineering, Acta Biomater., 2005, 1(6), 643-652.

24 G. Poologasundarampillai, et al., Poly(gamma-glutamic acid)/silica hybrids with calcium incorporated in the silica network by use of a calcium alkoxide precursor, Chem.Eur. J., 2014, 20(26), 8149-8160.

25 B. Granqvist, et al., Biodegradable and bioactive hybrid organic-inorganic PEG-siloxane fibers. Preparation and characterization, Colloid Polym. Sci., 2004, 282(5), 495-501.

26 O. Mahony, et al., Silica-Gelatin Hybrids with Tailorable Degradation and Mechanical Properties for Tissue Regeneration, Adv. Funct. Mater., 2010, 20(22), 3835-3845.

27 M. Manzano, et al., Mechanical properties of organically modified silicates for bone regeneration, J. Mater. Sci.: Mater. Med., 2009, 20(9), 1795-1801.

28 N. Miyata, et al., Apatite-forming ability and mechanical properties of PTMO-modified $\mathrm{CaO}-\mathrm{SiO}_{2}-\mathrm{TiO}_{2}$ hybrids derived from sol-gel processing, Biomaterials, 2004, 25(1), $1-7$.

29 Q. Chen, et al., Bioactivity and mechanical properties of PDMS-modified $\mathrm{CaO}-\mathrm{SiO}_{2}-\mathrm{TiO}_{2}$ hybrids prepared by solgel process, J. Biomed. Mater. Res., 2000, 51(4), 605-611.

$30 \mathrm{M}$. Kamitakahara, et al., Degradation of bioactive polydimethylsiloxane- $\mathrm{CaO}-\mathrm{SiO}_{2}-\mathrm{TiO}_{2}$ and poly(tetramethylene oxide)-CaO- $-\mathrm{TiO}_{2}$ hybrids in a simulated body fluid, J. Am. Ceram. Soc., 2004, 87(2), 235239.
31 A. J. Salinas, et al., Microstructure and macroscopic properties of bioactive $\mathrm{CaO}-\mathrm{SiO}_{2}-\mathrm{PDMS}$ hybrids, J. Biomed. Mater. Res., Part B, 2007, 81(1), 274-282.

32 M. Kamitakahara, et al., Bioactivity and mechanical properties of polydimethylsiloxane (PDMS)-CaO-SiO hybrids with different calcium contents, J. Mater. Sci.: Mater. Med., 2002, 13(11), 1015-1020.

33 S.-H. Rhee, Bone-like apatite-forming ability and mechanical properties of poly( $\varepsilon$-caprolactone)/silica hybrid as a function of poly( $\varepsilon$-caprolactone) content, Biomaterials, 2004, 25(7-8), 1167-1175.

$34 \mathrm{~S}$. H. Rhee, et al., Evaluation of a novel poly(epsiloncaprolactone)-organosiloxane hybrid material for the potential application as a bioactive and degradable bone substitute, Biomacromolecules, 2004, 5(4), 1575-1579.

35 X. Dieudonne, et al., Bioactive glass hybrids: a simple route towards the gelatin-SiO(2)-CaO system, Chem. Commun., 2014, 50(63), 8701-8704.

36 B. Yu, et al., Effect of Calcium Source on Structure and Properties of Sol-Gel Derived Bioactive Glasses, Langmuir, 2012, 28(50), 17465-17476.

37 Y.-S. Sun, et al., A low-temperature sol gel route for the synthesis of bioactive calcium silicates, Chin. Chem. Lett., 2013, 24(2), 170-172.

38 R. Marchal, et al., Biodegradability of polyethylene glycol 400 by complex microfloras, Int. Biodeterior. Biodegrad., 2008, 62(4), 384-390.

39 D. M. Pickup, et al., Preparation, structural characterisation and antibacterial properties of Ga-doped sol-gel phosphatebased glass, J. Mater. Sci., 2009, 44(7), 1858-1867.

$40 \mathrm{~T}$. Kokubo and H. Takadama, How useful is SBF in predicting in vivo bone bioactivity?, Biomaterials, 2006, 27(15), 2907-2915.

41 L. Wang, et al., Differentiation of human bone marrow mesenchymal stem cells grown in terpolyesters of 3hydroxyalkanoates scaffolds into nerve cells, Biomaterials, 2010, 31(7), 1691-1698.

42 Y. Liu, et al., Shell Cross-Linked Micelle-Based Nanoreactors for the Substrate-Selective Hydrolytic Kinetic Resolution of Epoxides, J. Am. Chem. Soc., 2011, 133(36), 14260-14263.

43 J. M. Yang, et al., Preparation of epoxy-SiO ${ }_{2}$ hybrid sol-gel material for bone cement, J. Biomed. Mater. Res., Part A, 2003, 64(1), 138-146.

44 P. de Caro, Z. Mouloungui and A. Gaset, Synthesis of alkyloxy (di)alkylamino propanols, hydroxy alkyloxy (di)alkylamino propanols, and the dimer compounds for use as fuel additives, J. Am. Oil Chem. Soc., 1997, 74(3), 235-240.

45 M. Vallet-Regi, et al., XRD, SEM-EDS, and FTIR studies of in vitro growth of an apatite-like layer on sol-gel glasses, $J$. Biomed. Mater. Res., 1999, 44(4), 416-421.

46 J. C. Elliott, P. E. Mackie and R. A. Young, Monoclinic hydroxyapatite, Science, 1973, 180, 1055-1057.

47 W. Liu, et al., Synthesis of bioactive poly(ethylene glycol)/ $\mathrm{SiO}_{2}-\mathrm{CaO}-\mathrm{P}_{2} \mathrm{O}_{5}$ hybrids for bone regeneration, Mater. Sci. Eng., C, 2012, 32(4), 707-711.

48 L. L. Hench and J. K. West, Biological applications of bioactive glasses, Life Chem. Rep., 1996, 13, 187. 
49 L. Russo, et al., Novel silica/bis(3-aminopropyl) polyethylene glycol inorganic/organic hybrids by sol-gel chemistry, Mater. Chem. Phys., 2013, 140(1), 168-175.

50 S. Midha, et al., Preconditioned 70S30C bioactive glass foams promote osteogenesis in vivo, Acta Biomater., 2013, 9(11), 9169-9182.

51 C. Wang, et al., Bioactive Nanoparticle-Gelatin Composite Scaffold with Mechanical Performance Comparable to
Cancellous Bones, ACS Appl. Mater. Interfaces, 2014, 6(15), 13061-13068.

52 I. D. Xynos, et al., Ionic products of bioactive glass dissolution increase proliferation of human osteoblasts and induce insulin-like growth factor II mRNA expression and protein synthesis, Biochem. Biophys. Res. Commun., 2000, 276(2), 461-465. 